\title{
State of Palestine
}

National Cancer Institute

\section{Source}

National Cancer Institute. State of Palestine. NCI Thesaurus. Code C20110.

A sovereign state in western Africa consisting of the West Bank and the Gaza Strip. Its capital is Jerusalem. 